\title{
Natural materials in housing construction in view of the current requirements of technical conditions - the content of Primary Energy Input
}

\author{
Radostaw Barek ${ }^{1, *}$, Tomasz Mielczyński ${ }^{2}$ \\ ${ }^{1}$ Poznan University of Technology, the faculty of Architecture \\ ${ }^{2}$ EDP TMA ARCHITEKT, BUILDGREEN DESIGN
}

\begin{abstract}
The article presents the reasons for using natural materials in former and contemporary housing construction. The possibilities of shaping contemporary housing architecture with the use of natural (unprocessed or low-processed) building materials in the light of the requirements of the Technical Conditions that should be met by buildings are discussed. The article discusses the results of calculating the U-value for different types of building partitions and the influence of the construction of the partition on the EU index and the cumulative value of Primary Energy Input in a given type of partition.
\end{abstract}

\section{Natural building materials - attempt to define}

Natural materials originating from local sources have recently become the subject of special interest in the last period ( 20 years). The sources of interest can be found both in the promotion of the idea of limiting $\mathrm{CO} 2$ to the atmosphere and in the search for an alternative to a commercial housing construction operating with highly processed building materials. Building new homes and apartments is now a great social need. The subsequent programs for building available flats, supported by public funds, do not comprehensively solve the existing demand for creating new places of living in decent financial conditions (implementation process, crediting, etc.). Attractive for a large part of the younger generation, striving to have their own home, a flat is a special way of implementation that launches processes that socialize the building process (cooperatives, COHABITAT, etc.). Building from natural materials such as clay or straw is often a contribution to the organization of social workshops, conferences, courses, especially regarding the broadly understood issues of eco-building.

Despite the growing popularity of the term "natural building", knowledge about natural materials does not include one, strict definition defining this group of products. For a clear presentation of the problem and a better introduction to the further content of the article, the

*Corresponding author: bar.pp@,wp.pl 
authors propose that "natural building materials" should be those that are possible to be built in unprocessed or slightly modified, i.e. having a minimal amount of Primary Energy Input in $1 \mathrm{~kg}$ of material. Fig. 1.

Another aspect that testifies to "environmentalism" understood as minimizing the impact of a building on the natural environment is its "locality". Building using materials obtained a short distance from the construction. Natural materials were used in housing construction always in connection with locally available raw material. The use of these materials in connection with technological improvement and aesthetic needs of local communities resulted in the creation of specific regional housing. Local materials used in the area of Poland's current borders are to a large extent wood, clay, and stone (e.g., limestone from south-east Wielkopolska and Małopolska). Locally, less frequently occurring material was used, such as: turf ore (near the Pyzdry Forest, Milicz, Łowicz).
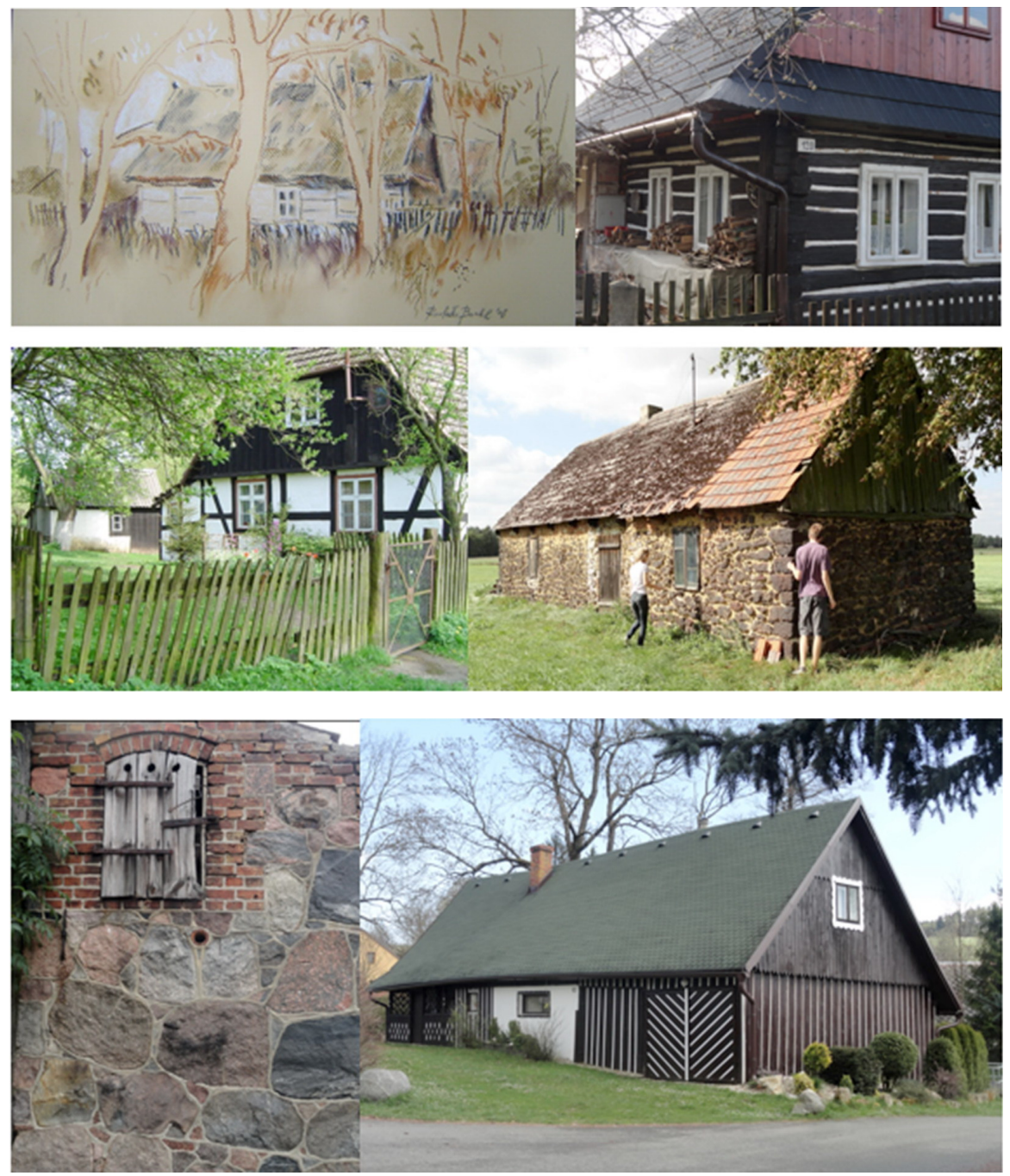

Fig. 1. Regional forms of architecture implemented using natural materials (1. Pyzdry Forest a house in a combined-spring construction, 2. a house in a wooden carving construction-Sudety, 3. a house in half-timbered construction - Western Pomerania, 4. a house made of turf ore Pyzdry Forest, 5. A farm building made of field stone - West Pomerania, 6th house with elevation with formwork - Sudety), fig. $5 \mathrm{x}$ fot. R. Barek. 
The material - clay was used both as the main structural material (eg. Rammed Earth Technology, ground tamped in the formwork "rammed earth"), the filler material structure (eg.: Construction of the lock, wattle and daub) and the insulating material in combination with the vegetable material most often the fiber ( straw, heather, etc.) and layered structures of the walls (timber frame*- patch-clamping wooden structure with an inner layer of coarse clay plaster - about $8 \mathrm{~cm}$ ).

Wood material was used in the carcass construction, mber frame - patch clamp or frame construction (frame wooden parts was performed with hardwood e.g.: oak). Wood also was used at the same time as insulating material (e.g. in the carcass construction, coronary design, or in the form of the formwork material was fulfilling the role of modern wind insulation).

Stone was used in the majority of cases as a construction and facade material. Additional insulating materials have been used to obtain thermal comfort in interiors.

Bog ore material due to its porosity was used both as a structural material and also as an insulating layer of insulation against soaking of moisture from the ground.

Organic materials (straw, heather, etc.) fulfilled the role of insulation materials or supporting structures as micro-reinforcement.

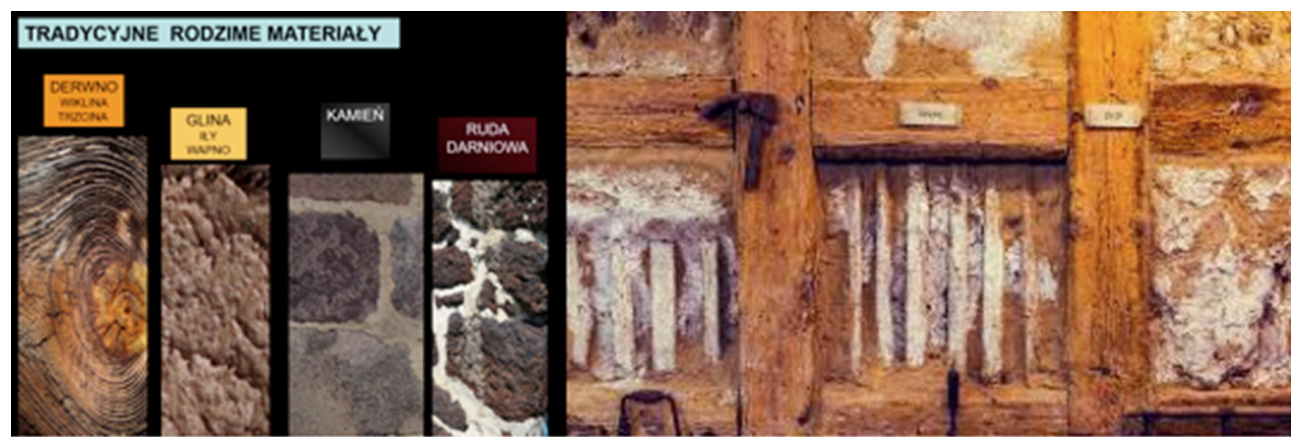

Fig. 2. Traditional materials and examples of wall construction techniques using natural materials wood, clay, straw, fot. R. Barek.

Contemporary use of natural materials is the subject to re-verification of the applicability of housing in current legal conditions. The use of natural materials of local origin requires designers to know about the properties and technology of their application. ${ }^{2}$

\footnotetext{
${ }^{2}$ Natural materials in Poland are classified as uncertified - because they require, inter alia, every examination of their properties. Certified materials in the general circulation already have the parameters and application procedures provided by the manufacturer, which release the designer from delving into the issue of allowing materials for use in a specific project.
} 

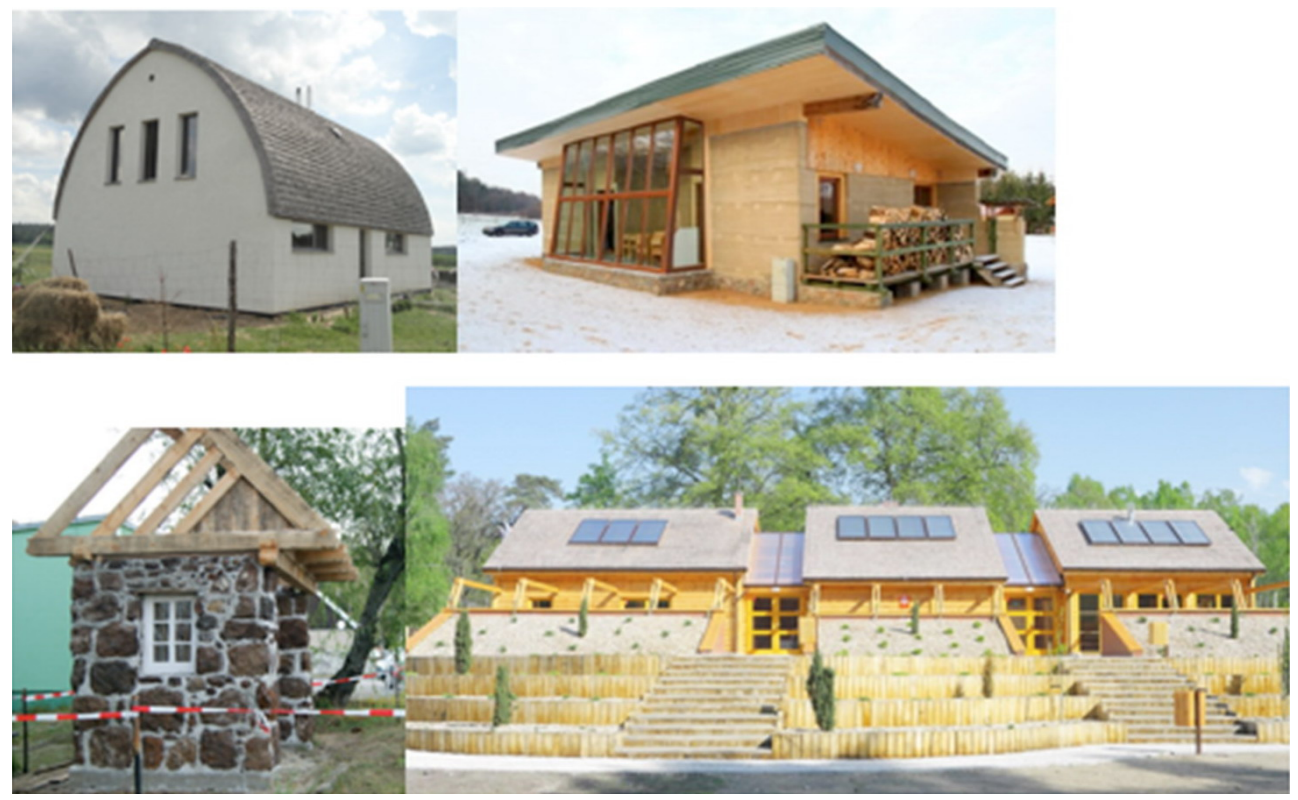

Fig. 3. Contemporary architectural objects in Poland, meeting the current requirements of the Technical Conditions, made with the use of natural materials. Autonomous house - wood - design arch. T. Mielczyński, house in Pasłęk - tamped down land, design architect T. Kelm, realization BMT Jurkiewicz, stop in the Pyzdry Forest - turf riverside designed by architect R. Barek, Forest Education Center Dziewicza góra-wood- design architect R. Barek) (4x photo RB).

The problem of using natural materials is both the quality and parameters of the obtained material (clay - bed, straw - humidity, etc.) as well as the parameters of resistance: to biological corrosion, erosion under the influence of weather conditions, fire resistance. Natural materials (MN) also show the superiority of parameters (e.g. interior microclimate), however, these parameters are not considered when compared with other materials (e.g. certified) with a high degree of processing.

\section{Natural materials confectioned}

Companies preparing natural confectionery materials ensure the stability of parameters often have certificates of the country of origin (e.g. Claytec, Picas) but in Poland the use of, for example, clay plasters is conditioned by the knowledge and experience of the designer and contractor. Performing contemporary research, e.g. fire resistance of natural materials, makes further doubts about the use of laminated walls of materials such as straw, clay, in a modern housing industry, becomes possible on a larger scale.

\section{Acquiring local material}

Acquisition of material, e.g. clay, is associated with the exploitation of the deposit. Currently, there are two ways of obtaining clay for construction purposes legally: 1) for one's own needs and, for example, brickworks, which have a permit for exploitation of minerals.

Straw requires very rigorous treatments during storage. High sensitivity to moisture absorption causes biological corrosion and mold growth to occur at a rapid rate. 


\section{Construction of contemporary walls (heat insulation requirements)}

The thermal insulation requirements for a building allow the use of walls made in a layered wall system with the use of specific properties of individual natural building materials. In modern design practice, the most common materials are straw in the form of pressed cubes or hemp in the form of a hempcrete composite as a filling of the frame structure and a stiffening element. [5] The natural thermal insulation materials also include confectioned fibrous wood fiber in loose form or in the form of pressed, light FLEX cubes. This material comes from industrial production, and because of that, it doesn't have one of the main features of natural materials - their heterogeneity and diversity depending on the source.

The ordinance of the Minister of Infrastructure regarding the Technical Conditions to be met by buildings and their location has defined a new level of thermal insulation of building partitions in residential buildings, for which the U-value from January 1, 2021 should be $\mathrm{U}=0.2\left[\mathrm{~W} / \mathrm{m}^{2} \mathrm{~K}\right]$.

The required thermal insulation thickness for obtaining such a coefficient for individual natural thermo insulation materials of organic origin is presented in Table 1.

Table 1. The required thermal insulation thickness to obtain the coefficient $U=0.2\left[\mathrm{~W} / \mathrm{m}^{2} \mathrm{~K}\right]$.

\begin{tabular}{|l|c|c|c|}
\hline \multicolumn{1}{|c|}{ Material } & Lambda $[\mathbf{W} / \mathbf{m K}]$ & Thickness & $\mathbf{U}\left[\mathbf{W} / \mathbf{m}^{2} \mathbf{K}\right]$ \\
\hline Wood Fiber - Flex & 0.038 & 0.14 & 0.2 \\
\hline Wood or Hemp Fiber & 0.04 & 0.15 & 0.198 \\
\hline Straw Bale - Across the fiber [120kg/m3] & 0.052 & 0.2 & 0.194 \\
\hline Straw Bale (Average) & 0.066 & 0.25 & 0.196 \\
\hline Straw Bale - Along Fiber & 0.08 & 0.3 & 0.198 \\
\hline Hempcrete [400kg/m3] & 0.1 & 0.36 & 0.196 \\
\hline Hempcrete [500kg/m3] & 0.12 & 0.45 & 0.198 \\
\hline
\end{tabular}

As a starting point for further research - the content of Primary Energy Input in $1 \mathrm{~m}^{2}$ of the building envelope - the co-ordinate was accepted. $U$ for the entire partition at $\mathrm{U}=0,158 \mathrm{~W} / \mathrm{m}^{2} \mathrm{~K}$ which corresponds to the "standard" thickness of the straw pressed in Strawbale technology available in Poland, which is $40 \mathrm{~cm}$. The aim of the study was to determine the content of Primary Energy Input in the partition and confirm the hypothesis about the desirability of using natural building materials (straw cubes) due to minimizing the content of primary energy built into the construction of external building partitions.

The production of each building material requires primary energy inputs. The amount of Primary Energy Input, expressed in kWh, is assigned to each type of building material and is a value describing the energy inputs from the combustion of fossil fuels for each kilogram of material produced. Calculation of the PEI amount begins with the extraction of the raw material and ends with "on the gate of the plant" - "From Cradle to Gate". The PEI quantities given in the tables do not take into account the Primary Energy needed to transport building materials to the construction site. 


\section{Description of the test methodology}

For simulation calculations, data from the "OkobilanzDaten im Baubereich" [2] database tables were used, and they are available at www.ecoinvent.com.

To calculate the content of the Primary Energy Input, a skeleton wall model with an area of $1 \mathrm{~m}^{2}$ filled with given insulation material was adopted. The thickness of the insulating material was adjusted accordingly to obtain for the entire partition a given $U\left(W / \mathrm{m}^{2} \mathrm{~K}\right)$ value $=0.15$, which was adopted as a reference for a wall filled with a standard bar of $40 \mathrm{~cm}$ thick pressed straw.

Due to different material density and various declared lambda coefficients [3], the thickness of the partition in each case is different and requires the use of a different amount of insulating material, which affects the final, total amount of Primary Energy built into the partition.

The remaining elements of the barrier needed for its physics-correct structural construction remain unchanged in the study (simulation) except for the cross-section of the wooden grid construction posts, which each time have a depth appropriate for the thickness of the insulating material required by the U-factor. In other words: the study was to answer the question of which of the insulation materials will result in the least total amount of Primary Energy Input built into the partition.

The results of calculations show that the final sums of Primary Energy calculated for the whole partition, related to one level of the U-factor are not intuitive, i.e. It is not the case that partitions based on thermal insulation from natural materials will result in the lowest PEI content in the partition (building). This is due to the cumulative impact of two features of natural insulation materials: their density and the declared lambda coefficient (for straw 0.008 or 0.052 - perpendicular to the stems of heat flow, because in a typical straw block, the fibers are mixed with each other, a lambda coefficient $=0.066$ was assumed for further calculations) [3] [4].

\section{Comparison of the amount of Primary Energy Input in $1 \mathrm{~kg}$ of insulating material $[\mathrm{kWh} / \mathrm{kg}]^{\star}$}

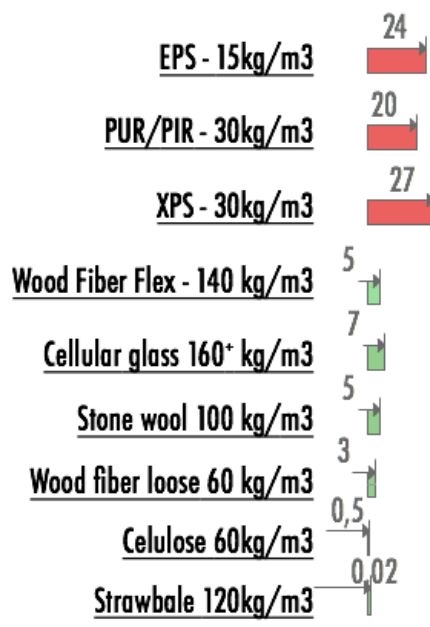

Fig. 4. Comparison of the amount of Primary Energy Input in $1 \mathrm{~kg}$ of insulating material. 
However, the most suitable plane for testing the content of Energy Input should be a reference to the material thickness corresponding to the given U-factor. In this case, the material mass ratio to the declared lambda coefficient is of great importance. This ratio is best for light insulating materials, such as EPS, XPS, which is clearly visible in the following list:

\section{Comparsion of Primar Energy Input in lsqm for $\mathrm{U}=0,15$ (material only)}

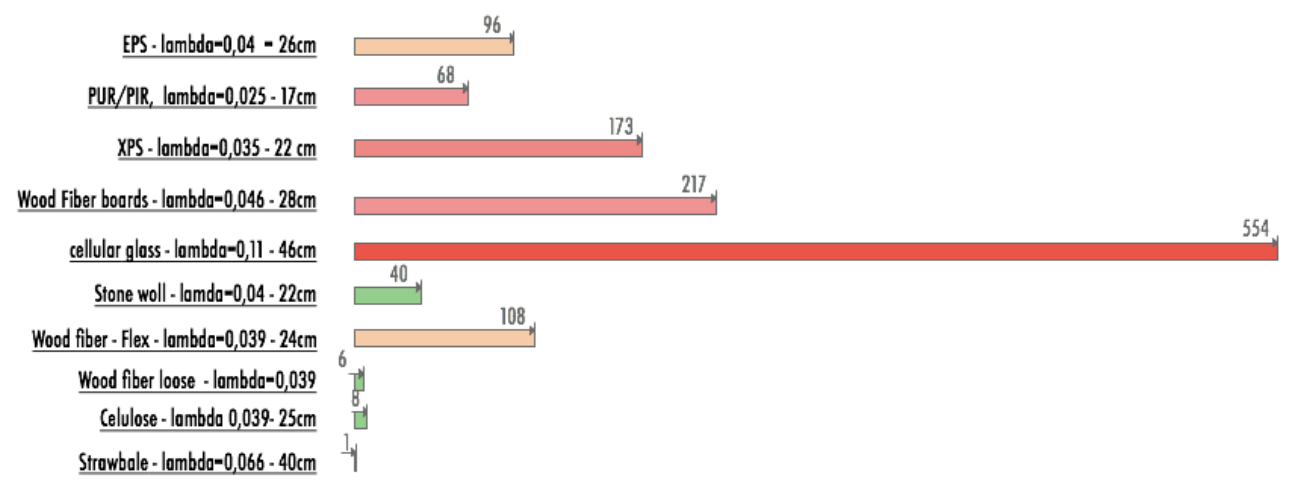

Fig. 5. List of the values of Primary Energy Input in $1 \mathrm{~m}^{2}$ of the wall, by T. Mielczyński.

If it were not taken into account any other factors and the full construction of the building partition, it turns out that for a given building, the least PEI have: loose wood fiber, straw cubes, loose cellulose fibers and soft stone and wood wool.

On the other hand, in fact, the discussed materials will always be used in combination with other elements and building materials necessary for the construction and proper functioning of the partition and only in such a comprehensive list should the issues of the amount of Primary Energy Input in a complete partition be investigated, where the insulation material is only one of elements forming the finished wall.

Comparsion of Primar Energy Input in 1sqm for U=0,15 (complete wall)

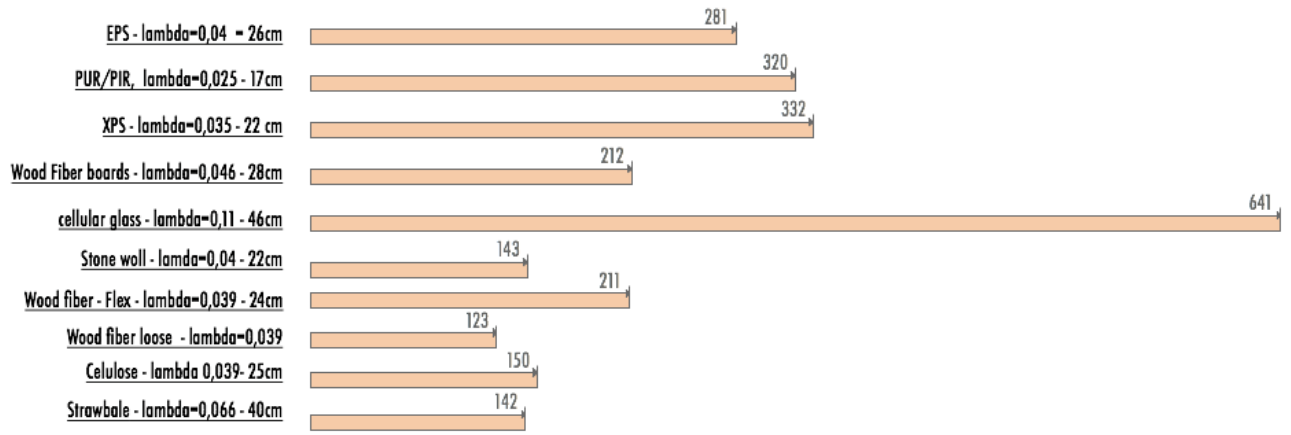

Fig. 6. Comparison of the amount of Primary Energy Input in $1 \mathrm{~m}^{2}$ of insulating material for defined U-value.

As it turned out, the results of PEI calculations made for the entire building envelope, where the thickness of the insulating material results in additional material (energy) expenditure on the construction of the load-bearing structure for the wall significantly differs from calculations taking into account abstract, clean insulation materials. 
The calculations showed that, considering PEI for all materials of the partition, its lowest content is characterized by a wall insulated with loose wood fiber, which has the best ratio of mass to insulation and PEI content in $\mathrm{kg}$ of material. The most energyintensive filling of the tested partition is foam glass, it is a bit surprising that PEI values for such stone wool, cellulose in the form of a loose embankment are actually equal.

The wall insulated with $22 \mathrm{~cm}$ thick stone wool has the same amount of PEI as the wall insulated with a straw block, although the PEI content for $1 \mathrm{~m} 3$ of material is for stone wool an order of magnitude greater than the straw bar.

However, the most important conclusion from the calculations made is the fact that the differences between the sums of PEI for particular types of partitions are relatively small, not larger than the order of magnitude. The ratio between the least and the most energyintensive partition is like 1 to 3 (the barrier insulated with foam glass should be rejected as impractical in the construction).

\section{Summary and conclusions}

The possibilities of using natural materials in modern housing are more widely promoted. Knowledge about technological conditions among architects, constructors and investors is limited by the lack of systemic education in this area.

In the common opinion there are many myths and simplifications related to the use of natural building / insulation materials in construction. The authors note the need for a reliable, systematic approach to the topic.

Another issue is to define the definition and purpose of the so-called Ecological construction. The presented research has shown that reducing this concept only to the calculation of PEI or Primary Energy Cumulated in the whole life cycle of a building may lead to surprising and far from intuitive solutions. According to the authors, the most important and difficult to overestimate feature of natural building materials is their negligible harm to the environment both at the stage of production (acquisition) and at the end of the life cycle of the building, when they are subject to natural biodegradation. Every other, and in particular highly processed, building material requires additional energy expenditures to properly dispose of and utilize the waste.

Housing construction with the use of natural materials, under the current legal conditions, has a chance to popularize with the widening of the circle of people with knowledge and skills to use it in specific projects. The continuation of research in the field of relationships: material-composite-building physics will allow for a wider practical application of natural materials by designers who are afraid of using local materials. The natural materials of local origin, used for centuries of past generations, also had their economic justification (proximity of transport, accessibility, universality of local technological knowledge). Also, nowadays the use of natural materials can be a support of economic factor combined with continuing research on these materials and dissemination of knowledge among the environments of designers, engineers, decision makers, investors and future home users.

\section{References}

1. Norma BN-62-8841-04 - Construction of clay - Walls of a collected clay - Technical conditions of performance and acceptance.

2. Okobilanzdaten im Baubereich: ecoinvent Datenbank, Version 2.2, www.ecoinvent.org - 04.2018)

3. Minke Gernot, (Clay Building Guide, Knowledge Gate 2013)

4. Brzyski Przemysław, (Construction with the use of limestone and hemp composite material characteristics, Building inspection 1, 2016) 